University of Nebraska - Lincoln

DigitalCommons@University of Nebraska - Lincoln

1957

\title{
The Life-Cycle of Diplostomum baeri eucaliae n. subsp. (Trematoda: Strigeida)*
}

Glenn L. Hoffman

US Fish and Wildlife Service

James B. Hundley

University of North Dakota

Follow this and additional works at: https://digitalcommons.unl.edu/usfwspubs

Part of the Aquaculture and Fisheries Commons

Hoffman, Glenn L. and Hundley, James B., "The Life-Cycle of Diplostomum baeri eucaliae n. subsp. (Trematoda: Strigeida)*" (1957). US Fish \& Wildlife Publications. 97.

https://digitalcommons.unl.edu/usfwspubs/97

This Article is brought to you for free and open access by the US Fish \& Wildlife Service at DigitalCommons@University of Nebraska - Lincoln. It has been accepted for inclusion in US Fish \& Wildlife Publications by an authorized administrator of DigitalCommons@University of Nebraska - Lincoln. 


\title{
THE LIFE-CYCLE OF DIPLOSTOMUM BAERI EUCALIAE N. SUBSP. (TREMATODA: STRIGEIDA)*
}

\author{
Glenn L. Hoffman and James B. Hundley \\ Bacteriology Department, University of North Dakota
}

During the summers of 1953, 1954, and 1955, many brook stickleback, Eucalia inconstans, from the English Coulee, a small stream in Grand Forks, were found infected with an unrecorded species of diplostomulum metacercaria; its life cycle has been reported in abstract (Hoffman, 1955). In 1953, 51 (82\%) of the 62 sticklebacks examined were infected, but in 1955 a much smaller number was infected; no exact records were kept in 1954 and 1955. The number of diplostomula per fish ranged from 0 to 335 . During the summer of 1956 lightly infected stickleback were also found in Turtle River, Kelly's Slough, and Freshwater Coulee.
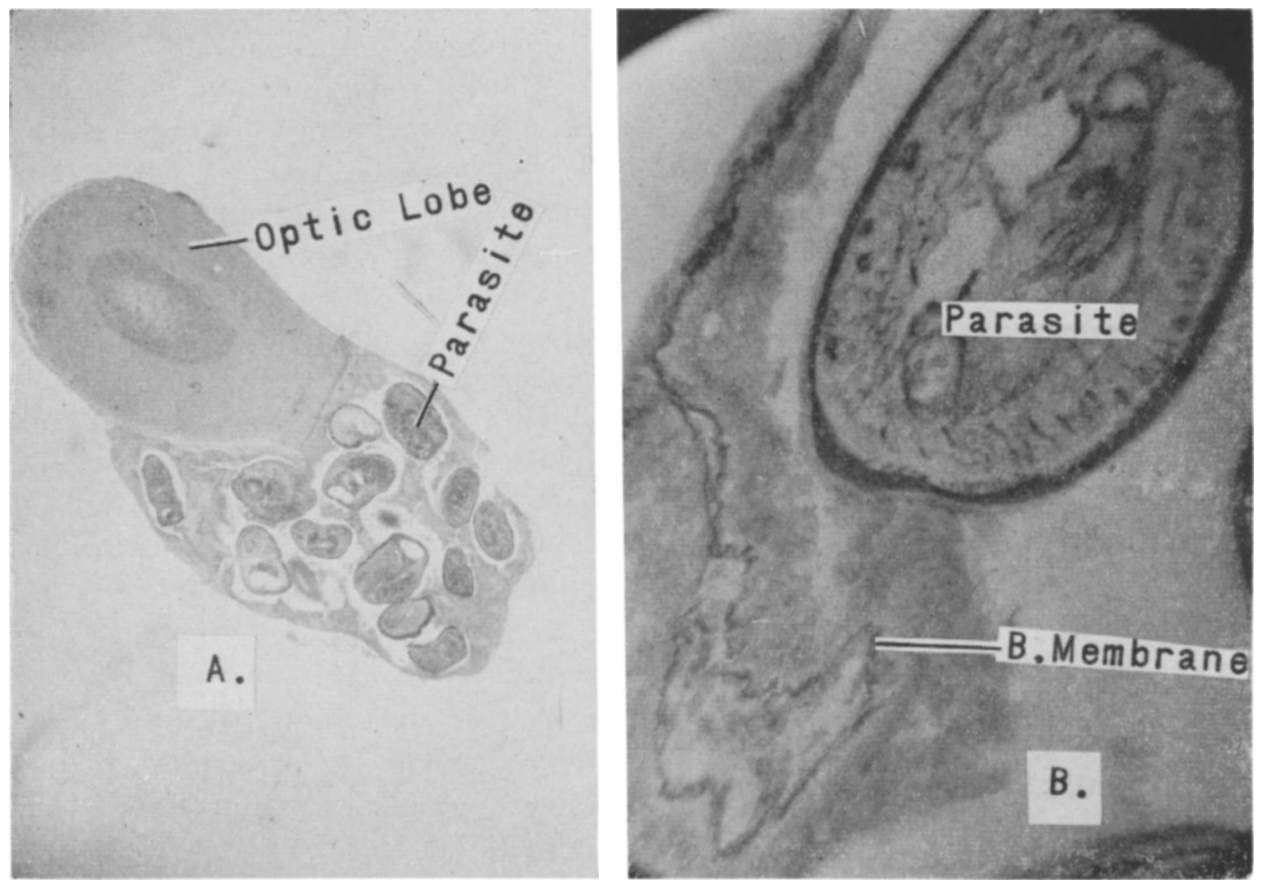

Figure A. Lateral section through optic lobe of Eucalia inconstans showing parasites in "sack."

FIGURE B. Cross section through "sack" stained with silver showing a metacercaria and the basement membrane of the metaplastic or hyperplastic columnar epithelium.

The diplostomula were located in the ventricles of the optic lobes and in greater numbers in a tumor-like cyst at the postero-lateral margin of the optic lobes (Fig. 15). The tumor-like structure consisted of an out-pocketing of the dura which enclosed the worms in a pocket above the pia mater (Fig. A). Surrounding each worm was a rather substantial amount of metaplastic or hyperplastic tissue resem-

Received for publication April 22, 1957.

* Supported in part by research grant B-855 from the Institute of Neurological Diseases and Blindness of the National Institutes of Health, Public Health Service. 
bling columnar epithelium (Fig. B), origin undetermined. Each worm appeared to remain in its own little niche in this tissue, although it had limited movement within it. In fresh material the diplostomula were seen actively moving around, each in its own niche. Experimental development of the proliferative tissue is being studied and will be reported elsewhere.

The fluid in the infected ventricles was cloudy with cells which in sections resemble leucocytes. The fluid in uninfected ventricles was clear.

No record of a comparable structure in fish could be found, although 5 species of strigeid metacercariae, none in North America, have been recorded from the brain of fish. The metacercaria of Diplostomum pelmatoides Dubois (Diplostomulum phoxini) has been studied from the brain of Phoxinus phoxinus in Europe by Ashworth and Bannerman (1927) and Rees (1955). Rees' description is, "On closer examination the worms do not appear to be free in the cavities of the brain, but seem originally to be located under the epithelium lining the cavities. This they raise up, there being an apparent proliferation of vacuolated tissue underneath in which the worms lie, each in its own little compartment, so that they do not touch one another." She reared the metacercaria to adult in young domestic ducks. In France, Arvy and Buttner (1954) have also completed the life cycle of Diplostomulum phoxini; metacercaria in Phoxinus laevis, adult in young domestic ducks, and sporocysts in Limnaea auricularia. Szidat and Nani (1951) have described Diplostomulum mordax and Tylodelphys destructor which invaded and destroyed tissue of the cerebellum, optic lobes, cerebrum, and optic nerves of the fish, Basilichthys spp., in Argentina, but they reported no tissue proliferation such as was found in the present study. Diplostomulum petromyzi-fluviatilis from the brain of the cyclostomes, Petromyzon fluviatilis and P. planeri of Europe, also does not produce such a structure (Brown, 1899). The only other strigeid reported from the brain of fish is Diplostomulum craniarium (Diesing) which has been reported only once (Leydig, 1853) from the cranial cavity of the Cobitis fossilis in Europe; it probably also did not produce such a tumor-like structure, although we have not seen the original paper.

There was no evidence of disease in the freshly collected fish, and infected ones that were held in aquaria died no more rapidly than did uninfected ones. The only other strigieds seen in the sticklebacks were 3 specimens of a diplostomulum about half as large as the present one. Although otherwise similar to the present species, it is believed to be different because it could not be reared experimentally.

The size of the fish examined ranged from 3.2 to $6.2 \mathrm{~cm}$. Few of those under $4 \mathrm{~cm}$ were infected and the 9 largest fish $(5.7$ to $6.2 \mathrm{~cm})$ possessed the heaviest infections. Hence the infection appears to be accumulative, rather than acquired only during the first 2 years, as is the case in infections with another strigeid, Uvulifer (Neascus) ambloplitis as reported by Hoffman (1953).

\section{The Experimental Adult}

Adults were obtained by force-feeding metacercariae to newly hatched unfed chicks and also by injecting metacercariae into the body cavity of newly hatched chicks. In the first experiments, 3 chicks were given 200, 350, and 400 metacercariae per os respectively. The chicks were fed commercial dog chow after the 
third day. The first chick yielded 43 egg-producing adults at autopsy on the third day; the second yielded 2 on the fourth day, and the third yielded 21 on the sixth day. The worms were found in the upper third of the small intestine and appeared normal. Later, 6 chicks were given 120 to approximately 1,500 metacercariae each and autopsied at 3 to 13 days; these chicks yielded 2 to 159 worms each. There is no correlation between numbers of worms given and number recovered, or the length of time in the chick and the number recovered; it is possible that many of the metacercariae were not yet mature. One hundred sixty, 400, 300 and 100 metacercariae respectively were injected into the visceral cavities of 4 chicks. Forty-seven egg-producing adults were recovered from the first chick at 5 days; 11 were recovered from each of 2 chicks at 18 and 20 days, and none were recovered from the fourth chick. Egg-producing adults were first recovered at 3 days. Eggs recovered from both intestine and visceral cavity, as well as from worms, appeared normal and many developed active miracidia when incubated in water.

In attempts to find other experimental hosts, the following results were obtained from force-feeding experiments: (1) One half-grown grackle, probably Quiscalus sp., fed about 150 metacercariae, died 2 days later; no trematodes could be found. (2) One domestic pigeon, Columba livia, was fed 223 metacercariae; no trematodes were found at autopsy 5 days later; this bird was fed corn. (3) Two wild gulls, Larus franklini, dewormed with dibutyl tin dilaurate, were fed many naturally infected fish over a period of 8 days. At autopsy, 1 contained no strigeids, the other contained 1 Diplostomum spathaceum. (4) One fledging mourning dove, Zenaidura macroura, fed 175 metacercariae, died 3 days later; 5 immature specimens were recovered in which the vitellaria were not discernible but the gonads were nearly mature; this bird was fed condensed milk. (5) One screech owl, Otus asio, fed 98 metacercariae, yielded 2 ovigerous adults 4 days later which were identical with the ones obtained from the chicks; it is probable that they came from the experimental feeding. This bird was fed laboratory mice.

In addition to the experimental attempt to find the final host, the following birds, collected in the locality of the infected fish (Aug. 20-Oct. 1), have been examined and found negative for Diplostomum baeri eucaliae, although it is quite certain that most, if not all, had ample opportunity to become infected: 2 kingfishers, Ceryle alcyon, 2 pied billed grebes, Podylimbus p. podiceps; 1 blue-winged teal, Anas discors; 1 greater yellow legs snipe, Totanus melanoleucas; 3 lesser yellow leg snipe, Totanus flavipes; 5 bittern, Botaurus lentiquinosus; 1 killdeer, Charadrius v. vociferous; 1 semipalmated sandpiper, Ereunetes pusillus; 1 mourning dove, Zenaidura macroura; 3 marsh hawks, Circus cyaneus hudsonius; one great blue heron, Ardea h. herodias; and 1 domestic white duck.

The only naturally infected host found was the wild mallard, Anas p. platyrhynchos; one fledgling collected August 2, 1956 from the Freshwater Coulee yielded 5 adult $D$. baeri eucaliae, one collected October 1, 1956 was negative and 2 collected October 10, 1956 yielded 2 and 1 adults respectively. These worms were indistinguishable from the ones reared in the chicks, and eggs and sperm were present. Therefore, it appears to us that the mallard serves as the natural host in this area and that other birds, the mourning dove and the screech owl at least, may serve as "accidental hosts". 
The Adult: (All measurements in millimeters)

Five living adults from the chicks ranged from 1.35 to 1.8 in length and $c a 0.48$ in greatest width. The hindbody, $0.75-0.96$ in length, originates about midway in the worm and, in the usual position, extends dorso-posteriorly at $65-80^{\circ}$ (Fig. 2) ; this flexure is also present after hot fixation and death in saline-it is probably the "normal" position. Thirteen live eggs measured $0.102(0.092-0.111)$ by $0.059(0.054-0.064)$, operculum 0.016 in diameter.

Specimens fixed in hot Bouin's solution, stained, and mounted in permount (Figs. 1, 2) gave the following average measurements: Total length -1.42 ; forebody $0.864 \times 0.436$; hindbody $0.568 \times 0.366$; oral sucker $0.074 \times 0.074$; prepharynx 0.004 ; pharynx $0.063 \times 0.05$; esophagus 0.042 ; ventral sucker $0.097 \times 0.097$; holdfast organ $0.176 \times 0.191$; ovary $0.081 \times 0.99$; eggs $0.103 \times 0.59$; first testis $0.139 \times 0.172$; and second testis $0.163 \times 0.209$. Number of eggs in uterus, 0-6. Paratype deposited in U. S. National Museum Collection as number 55620.

The adult worms were present in the anterior one-third of the intestine. The forebody lies at about a $90^{\circ}$ angle to the intestine and is completely submerged in the mucosa. In some instances, in cross sections, the oral sucker can be seen almost in contact with the submucosa.

There were mucosal hemorrhagic spots around most of the worms, and the mucosa was degenerate to a small degree at points of contact with the worm, but the damage did not seem to be extensive. The hemorrhagic spots were still present at 13 days, however, which was the largest period of observation. We have noted that these hemorrhagic areas are not present in gulls naturally infected with Diplostomum spathaceum or hawks infected with other strigeids even when there are numerous worms present.

In France, Arvy and Buttner (1954) reared Diplostomulum phoxini to adult in young domestic ducks but did not designate their adults as $D$. baeri because of the improbability of the recorded final hosts, marine birds, obtaining inland material. Rees (1955) in England, reared Diplostomulum phoxini to adult in young domestic ducks but designated them as Diplostomulum pelmatoides. We are not certain, therefore, whether Diplostomulum phoxini develops into Diplostomum phoxini, Diplostomum baeri, and/or D. pelmatoides, or if there are actually 2 or 3 species of worms concerned.

Morphologically our worm does not appear to differ from Diplostomum baeri Dubois, 1937, except that the gonads are smaller. Dubois (1955) has kindly examined 2 of our specimens and states he is convinced that it is a form type of $D$. baeri as it occurs in Europe in Stercoraires. In spite of the remarkable similarity, we believe it wise to give attention to apparent physiological differences; i.e., $D$. baeri has been found only in a species of Stercorariidae in Europe, whereas the present worm will develop in unfed chicks, mourning doves, the wild mallard, and the screech owl, but will not develop in gulls (Laridae) which are in the same order as Stercorariidae; members of the Stercorariidae are not found this far inland. Further, diplostomula of the present species have been reported only in this study. It is therefore proposed that the present worm be designated as Diplostomum baeri eucaliae n. subsp. because of its prevalence in the stickleback in this area.

\section{The Miracidium}

Eggs recovered from both the intestinal and visceral experimental adults were incubated successfully in 6-cm Petri dishes in tap water dechlorinated with sodium thiosulfate and incubated at approximately $23^{\circ} \mathrm{C}$. Miracidia were first detectable in the eggs at 10 days; free swimming forms were first seen at 12 days. The swimming motion was rather rapid with the usual rotation of the body. (The following measurements are in microns.) 
Five live miracidia (Fig. 3) were 132 (118-154) by 38 (30-49). Cilia were 10 to 11 long. Lateral papillae 4 to 5 long and about 2 wide at their widest. Nature of the papillae not determined; they appeared more like secretions of some sort than definite organs. On one occasion dorsal and ventral papillae were also observed at about the same distance from the end of the larva. In addition to the lateral papillae which have been described from many species, there were very small ones about 2 microns anterior to them and about 2 long. Pigmented eye spots 9 to 11 long and about 7 to 8 wide from the dorsal aspect, very close together, and flattened on the outer margin but nearly round when seen from the side. Lens 4 by 5 in diameter could be seen in specimens flattened on a slide. Penetration organ not easily seen and nearly cylindrical, measuring about 15 long and 5 wide. Two pairs of flame cells, but excretory tubules not determined. Penetration ducts easily seen but penetration glands not ascertained. Many large vacuoles about 10 microns in diameter present in most of the specimens studied.

\section{The Sporocysts}

Twenty-four Physa spp., 14 Helisoma anceps, Menke, and about 75 Stagnicola palustris Mueller and Stagnicola palustris elodes (Say) were exposed to the miracidia. All snails were laboratory-reared. None of the Physa or Helisoma became infected but 17 of about 70 Stagnicola did. Thirteen of the infected ones were $S$. palustris elodes; the remaining 4 were $S$. palustris. Cercariae were first observed after 30 days of development at $22-28^{\circ} \mathrm{C}$. At this time the entire digestive gland, and remaining viscera to a lesser extent, were a tangled mass of mother and daughter sporocysts. At a later time when the cercarial production had become very low, the larger mother sporocysts could be found among the viscera other than the liver, and only daughter sporocysts were present in the liver. All measurements are in millimeters.

Mother sporocyst-14 days (Fig. 4) :

Five specimens of 14-day-old sporocysts were found in the mantle of 1 experimental snail. These were $0.266(0.238-0.294)$ by $0.051(0.039-0.068)$ and very similar to the early stage of Diplostomum flexicaudum as shown by Cort, Ameel and Van Der Woude (1951). The anterior end of one was seen to contract, producing annulations. The germ balls were not studied in detail but were about 0.03 by 0.015 .

Mother sporocyst-22 days:

Only one specimen was recovered; it was in the mantle, was fully developed and was producing daughter sporocysts.

Mother sporocysts—mature, 30 days or more (Fig. 5):

Seven sporocysts fixed in hot $10 \%$ formalin measured $18.9(8.1-25$.) by $0.146(0.09-0.202)$. A birth pore was not ascertained but the anterior end was capable of invagination. The smallest embryos inside the sporocysts were about 0.06 in diameter and the largest nearly mature daughter sporocysts were 0.8 by 0.04 . Some were nodular, especially the oldest ones observed (45-67 days post infection) ; these older ones contained very few cercariae and looked "spent".

Daughter sporocyst-22 days post infection:

At this time there were very active daughter sporocysts in the viscera but not in the digestive gland itself. Six live ones measured 0.3 to 0.68 by 0.03 to 0.06 . Three fixed in hot Bouin's measured $0.397(0.377-0.422)$ by $0.065(0.06-0.075)$. Germ balls were very numerous but there were no developmental forms recognizable as cercariae yet.

Daughter sporocyst-26 days post infection:

Many daughter sporocysts were present in the liver at this time. Forms recognizable as developing cercariae, but not mature cercariae, were present in them. Seventeen sporocysts fixed in hot Bouin's measured $1.947(0.75-3.6)$ by $0.106(0.09-0.135)$.

Daughter sporocyst-mature, 30 days or more (Fig. 6 ):

Ten freshly dissected sporocysts measured $1.458(0.55-4.4)$ by $0.067 \quad(0.05-0.1)$. The smallest ones contained not fully developed cercariae. Near the anterior end of the sporocyst was a slightly thickened cuticular ridge which gave the appearance of small "ears" under the compound microscope. Anterior to the ridge the sporocyst is invaginable. Just posterior to 
the ridge is the prominent birth pore. At least 20 flame cells are present in the younger sporocysts. Very small (about 0.001 ) spine-like structures are seen at the very anterior tip. Small yellowish granular-appearing structures about $0.001-0.002$ in diameter are seen in the cuticle; we do not otherwise know their nature.

Seven experimentally infected snails were kept at 4-6 $\mathrm{C}$ from September till March to simulate a North Dakota winter, but although cercariae were being produced in September, no sporocysts could be found upon dissection in March, a period of about 6 months; this indicates that the infection does not overwinter in snails.

\section{The Cercaria}

The cercaria (Fig. 7) was studied alive and fixed from 14 experimentally infected Stagnicola palustris and Stagnicola palustris elodes, using bright field and phase microscopy. Nicotine sulfate (Black Leaf 40) 1 ppm and menthol-Tween $80(0.25 \%$ menthol in $5 \%$ Tween $)$ were used successfully as anesthetics. Neutral red, Nile blue sulfate and Bismark brown were used as intra-vital stains with and without the anesthetics. All measurements were made on 10 random specimens fixed in hot formalin as described by Cort and Brackett (1937) and are given in microns.

Description of cercaria (Measurements in microns):

Length of body 203 (170-245) width 37 (30-49). Tail stem length 232 (202-248), width 34 (30-42); furcal length $193(180-235)$; furcal width 27 in greatest diameter. Penetration organ pyriform but long and narrow when fixed; length 62 (55-76), width 25 (24-37). Diameter of ventral sucker $26(22-30)$. Distance from middle of ventral sucker to posterior end of body 93 (88-99). Oral opening terminal; digestive tube inside penetration organ gives the appearance of a coiled structure with phase microsscopy; prepharynx short, about 7 long; pharynx about 13 by 10 . Esophagus bifurcating about half way between pharynx and ventral sucker ( $c a 15)$. Ceca extend nearly to posterior of body, conspicuous and enlarged terminally to about 11 in diameter. Four large penetration glands behind the ventral sucker and ventral to the ceca. Anterior pair of glands usually tandem but sometimes nearly side by side, the other 2 usually lobed and side by side behind the anterior pair. The conspicuous penetration gland ducts pass anteriorly, penetrate the oral sucker in which they are dilated, and open terminally lateral to the oral opening.

Excretory system: Six flame cells on each side of the body usually difficult to ascertain; connecting tubules not determined; bilobed bladder at posterior of body with small "Island of Cort"; 1 pair of flame cells in each side of the tail stem; cilia in the posterior bladder arm in the anterior of the tail stem.

Three groups of small forward-projecting recurved spines, about 2 long, just dorsal to the openings of the penetration ducts and oral opening, hard to see. A band of irregular, small, closely set spines, each about 1.5 long, extends about 22 microns from the anterior end to about half-way past the penetration organ. First of 9-11 evenly spaced rows of spines which are $c a$ 3.5 long at about 40 from the anterior end. Few additional scattered spines at each lateral aspect of first 2 rows. The rows of spines completely encircle the cercaria except the last 1 or 2 rows which have no ventral spines. The last row of spines usually at about the level of the center of the ventral sucker. During "shimmy" motion in menthol-Tween 80 plus Nile blue sulfate, small constrictions form across the body between each of the rows of spines. Rarely, a larger constriction occurs at the posterior level of the ventral sucker. Small, irregularly spaced spines about 2.2 long cover remainder of body. Three irregular rows of spines on the inner portion of the ventral sucker. One pair of body flagellets at the postero-lateral position of the body. Numerous transverse ridges about 4.5 wide throughout the length of the tail stem which probably correspond to the lateral sub-cuticular cells, the nuclei of which are about 3.5 in diameter. About 10-12 flagellets $c a$ 10-12 long, on each side of the tail stem, also flagellets on the ventral and dorsal surfaces. The flagellets, perhaps under stress, seemed to "melt down" to globular structures; we have also seen this condition on the cercaria of Crassiphiala bulboglossa, another strigeid (Hoffman, 1956). Some of these "globs" were seen to shoot out an incomplete flagellet. To the best of our knowledge the function of these flagellets is unknown. A few small scattered spines $c a 1$ long on the tail stem. Six pairs of nucleated caudal bodies; the 3 anterior pairs nearly opposite each other and elongate to round, sometimes stellate; the 3 posterior pairs elongate, and the last 2 pairs usually not opposite in position; the posterior half of the entire caudal body process slightly rotated. Four easily seen rows of spines on the 
furcae (Fig. 8), and 1 or 2 rows of very small spines on, or near, the edges. Furcae terminate with prominent nipple-like processes $c a 3$ long by 2 in diameter.

When undisturbed, the cercariae hang vertically with the body down, the tail stem straight, and the furcae well separated. The body is slightly bent ventrad. The worms are evenly distributed in the water and only a few are in motion at one time. Periodically, they swim upwards several times their length. Under laboratory conditions they emerge in relatively small numbers throughout the day and night. They are positively phototropic.

Four lots of cercariae were tested for longevity at $24-27^{\circ} \mathrm{C}$; live cercariae were last seen in these bottles 28, 32, 35 and 35 hours respectively. One lot was tested at a higher temperature, $23-30^{\circ} \mathrm{C}$, and live cercariae were last seen at 23 hours. Infected snails, although otherwise apparently healthy, did not yield cercariae for more than 11 days. Fourteen infected snails produced cercariae in large to moderate numbers for 1 to 8 days, average 4.3, and in small numbers for 5 to 9 days more, average 6.6, a total of 11 days. Four infected snails produced an average of 9,672 cercariae for a 24-hour period during the peak of their production.

\section{Discussion}

Cercaria $D$. baeri encaliae is probably very similar to the European cercaria of Diplostomum phoxini ${ }^{1}$ as briefly described by Arvy and Buttner (1954). They state that the cuticle is spined to nearly mid-body but do not mention rows of spines. The present species has 9-11 rows and there are also scattered spines on the rest of the body. The present species is also about $25 \%$ larger. Cercaria D. baeri eucaliae differs from Cercaria scudderi Oliver, 1941, in the following respects: The characteristic anterior constrictions as recorded for $C$. scudderi are usually not present. There are at least 8 complete rows of spines, whereas $C$. scudderi has only 5 complete rows. There are 8 flame cells on a side instead of 10 as in $C$. scudderi.

Cercaria D. baeri eucaliae has the following in common with $C$. diplostomum flexicaudum Cort and Brooks, 1928; C. laruei Cort and Brooks, 1948; C. diplostomum spathaceum (Cercaria C of Szidat) ; C. helvetica XV Dubois, 1927 ; C. chrysenterica, Miller, 1923; and C. chromatophora Brown, 1931: Two pairs of posterior penetration glands, caudal bodies present, body spines in rows, anterior forwardpointing spines, and no post-acetabular constriction when standing in water. However, C. diplostomum eucaliae differs from: (1) C. diplostomum flexicaudum in not having a bent tail when hanging in water and having 9-11 rows of body spines instead of 18, (2) C. laruei in localizing in the fish brain instead of lens, and having 9-11 rows of spines instead of 18, (3) C. modicella in being much larger and in having 9-11 rows of spines instead of 17, (4) C. diplostomum spathaceum in having 6 pairs of caudal bodies instead of 30, (5) C. halvetica in not having furcal fins, (6) $C$. chrysenterica in having 9-11 rows of spines instead of 9 bands of 3 rows each, (7) C. chromatophora in not having yellow pigment, in having spines in rows, and tail stem only a little longer than the body instead of twice as long.

Concentration of cercariae:

Various methods of concentrating cercariae have been reported. These include the flask side arm phototropic migration method of McMullen and Beaver (1945),

${ }^{1}$ After this paper went to press Rees, G. (1957) Parasitol. 47 (1, 2) : 126-137 described the cercaria of $D$. phoxini in England. 
and removing the excess water through the walls of a porous porcelain container (Pellegrino and Macedo, 1955). In this study large concentrations of living cercariae were easily obtained by slowly filtering off the excess water through a Berkefeld $\mathrm{N}$ virus filter. A large size filter (350-ml capacity) was used and the $140 \mathrm{ml}$ remaining in that filter were then placed in a small size filter (50-ml capacity) and the remainder concentrated down to $5 \mathrm{ml}$ of living cercariae.

Experimental Infection and Development of the Metacercaria Experimental infection:

Cercaria were allowed to accumulate in the snail bottles for 4 to 12 hours and were then poured into gallon jars containing the fish and about a liter of dechlorinated water. Sticklebacks were readily infected, but no metacercariae were recovered from exposed fatheads, Pimephales p. promelas, or top minnows, Fundulus diaphanus menona although skin hemorrhages were noticed. Large concentrations of cercariae killed the stickleback in a few hours; hence it was desirable to determine the approximate numbers of cercariae to use in order to obtain maximum numbers of metacercariae. The following results were obtained: (some mortality was probably caused or influenced by aquarium conditions).

(1) 33 fish, 200 cercariae each-death in 1-365 days with 48 (17-101) metacercariae.

(2) 60 fish, 240 cercariae-death in 1-43 days with 133 (27-370) metacercariae.

(3) 1 fish, 250 cercariae-death in 12 hours; cercariae not recovered.

(4) 28 fish, 270 cercariae each - death in 61/2hours-30 days with 48 (8-173) metacercariae.

(5) 8 fish, 400 cercariae-death in 3-5 hours, cercariae not recovered.

(6) 1 fish, 500 cercariae-death in $3 \frac{1}{2}$ hours, cercariae not recovered.

(7) 5 fish, 1,000 cercariae each-death in $2-2 \frac{1}{2}$ hours, cercariae not recovered.

(8) 1 fish, 2,000 cercariae-death in $2 \frac{1}{2} 2$ hours, cercariae not recovered.

(9) 1 fish, 3,375 cercariae-death in 2 hours, cercariae not recovered.

The above results indicate that a single exposure to 200 or more cercariae can be fatal to at least some of the fish, although only about one-fourth of the larvae can be recovered later as metacercariae. In an attempt to produce more massive experimental infections, fish were exposed to smaller numbers of cercariae on different days in order to minimize the resulting hemorrhaging due to migrating larvae; the results follow:

(1) 70 fish plus 150 cercarie each followed by

150 more cercariae in 3 days, followed by

100 more cercariae 5 days later-death in

10-95 days; 132 (58-187) metacercariae recovered.

(2) 10 fish plus 200 cercariae each followed by

150 more cercariae in 10 days, followed by

100 more cercariae 1 day later -9 alive at 50 days;

1 lived 8 months; 1 had 106 metacercariae.

\section{Development of the metacercaria:}

Larvae were recovered from experimental fish at intervals and studied alive and fixed in hot Bouin's, stained and mounted. Serial sections of infected fish were also studied. (Measurements in millimeters.)

35 minutes to 24 hours-Many larvae recovered from blood and optic lobes, a few from olfactory lobes, skin, gills, optic nerve, skeletal muscle, cornea, and retina. Much evidence of hemorrhage in heavy infections, particularly behind the eyes and at the postero-lateral part of the brain. Also much hemorrhaging of the viscera, presumably the cause of death in extremely heavy fatal infections. Dawes 
(1952) has reported the death of fish caused by cerebral hemorrhage after heavy experimental infections with Cercaria $C$ of Szidat $=$ Diplostomulum volvens. In cross section many larvae were seen in the blood vessels of the head and gills; we assume that many penetrate the gills and use the blood vessels in migrating to the brain. Fewer larvae were seen in cross sections of the body, and particularly the posterior part, than in the head region, indicating that more larvae do enter the head region than the rest of the body. The larvae were morphologically the same as the cercarial body.

3 days-All of the larvae recovered were distributed throughout the brain and in heavy infections there was still much hemorrhaging at the postero-lateral part of the brain.

Larvae very active, ca $0.170 \times 0.052$ alive and $0.208 \times 0.54$ fixed and mounted. Penetration glands and ducts, spines still present. No evidence of holdfast or hindbody development.

5 days (Fig. 9)-Most of the larvae were in the optic lobes, in the nervous tissue itself as well as just under meninges and in the optic lobe ventricles. Several were seen in the eyes invading the rod and cone layers. Fixed and mounted larvae were $c a 0.314 \times 0.104$. In live specimens the region of the holdfast is a slight indentation, the spines are still visible, and there is an indentation of lateral sucker and hindbody development. Black pigment, presumably from the retina, was seen in the ceca of these worms.

9 days (Fig. 10)-Most of the metacercariae are grouped in the beginning of the sac-like structure at the postero-lateral margins of the optic lobes, perhaps because there is a rather significant space between the brain and the roof of the cranium of the stickleback at this point. A smaller number of metacercariae is usually in the ventricles of the optic lobes and an occasional worm is still present in the brain tissue of the optic lobes. Blood clots from the hemorrhages are still present. Live worms $c a 0.470 \times 0.216$, fixed $0.489(0.397-0.554)$ by $0.175(0.156-$ 0.198 ) and hindbody, lateral suckers, and holdfast organ are well formed. The larva looks much like a mature metacercaria but there is no evidence of the reserve excretory system, including the calcareous corpuscles.

11 days - The metacercaria appears almost identical with the mature larva, and although the main reserve excretory system tubules can be seen, the calcareous corpuscles cannot be seen; granules (0.001-0.002), believed to be their precursors, can be seen grouped around small branches of the reserve system; however, no tubules connecting these granules to the reserve system could be seen.

14 days - The granules are now round and ca 0.004 in diameter.

16 days - The largest granules are now 0.005 in diameter.

18 days (Figs. C, 11, 12, 13, 14)-The granules are now typical calcareous corpuscles, $0.004-0.007$ in diameter, and the metacercariae cannot be distinguished from the older "mature" metacercariae.

In no instances were experimental larvae found in the lens of the eye although an occasional one was found in the posterior chamber; we do not know if these survive more than 60 days.

To determine at what age the metacercariae first become infective, various ages of larvae were fed to each of 12 chicks by dropper tubes inserted into the esophagus; the results follow: 

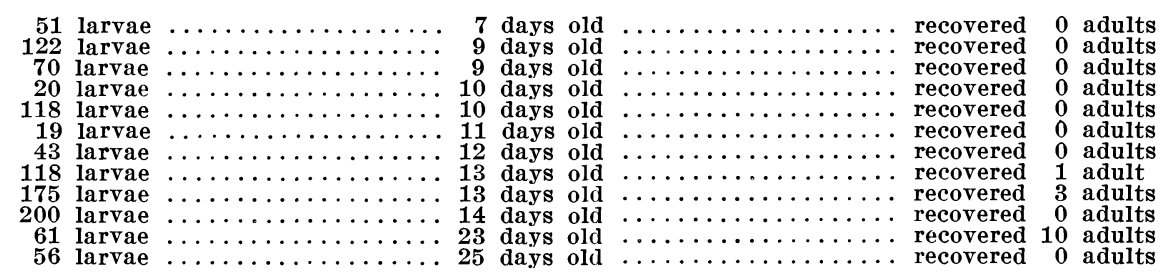

From the above results it is probable that the metacercariae become infective between 13 and 23 days. The small numbers recovered are probably due to the fact that the chick is an unnatural host. It is probably coincidental that the calcareous corpuscles appear at about the time the larva becomes infective; no other morphological change was noticed at this time. We have kept sticklebacks experiimentally infected with at least 101 metacercariae for a period of 1 year and believe that the larvae would live much longer.

The mature metacercaria alive (Fig. C) (measurements in millimeters):

When freed from the brain the metacercaria contracts and expands very actively. Normal inactive size $c a 0.65 \times 0.320$ (Fig. C) ; fully stretched, $c a 0.7$ long; contracted, $c a 0.5$ long $\times 0.38$ wide. Hindbody distinct from forebody in typical strigeid fashion, conical shaped, projects slightly dorsally, is very mobile, and measures 0.076 to 0.150 in length depending upon its state of activity. Forebody typically spatulate, moderately concave, posteriorly covered with very minute spines which are a little larger on the holdfast organ. Lateral suckers very prominent, ca 0.03 in diameter, deeply cupped $(0.047-0.06)$; at times completely everted (Fig. 14) ; very prominent muscles extend posteriorly from them. Oral sucker nearly spherical, $c a 0.065$ in diameter. Prepharynx very short. Pharynx longer than wide, measures $c a 0.05$ long. Esophagus $c a 0.02$ long. Intestinal crura visible under cover glass pressure; they curve around the ventral sucker and holdfast organ and terminate in the hindbody. Ingested fish brain cells present in the crura in cross sections and in "regurgitated" material. Ventral sucker just anterior to the holdfast organ and $c a 0.09$ in diameter. Holdfast organ nearly at the posterior end of the forebody, almost spherical from the ventral aspect, and $c a 0.15$ in diameter.

Excretory system visible under slight cover glass pressure (Fig. C) ; it is nearly identical with that of D. phoxini (Faust), 1918 and D. browni, Hughes, 1929, with a bi-lobed bladder and 4 main excretory tubules. The bladder appears more slender in our specimens; however, this may be due to less pressure; the shape is also slightly different. The bladder empties about every 75 seconds.

The calcareous corpuscles lie in little sacs in the termini of the reserve excretory tubules. They are very numerous (Fig. 12), spherical, and measure 0.004 to 0.009 ; no oval ones were seen as has been reported for $D$. phoxini. The reserve excretory system appears to receive excretory material from the main excretory system which is fed excretory material by the flame cells. It is not known if excretory material passes from the worm into the termini of the reserve system, if the reserve system is simply a storage organ, or if it has a different function. In any event, no function of calcareous concentrations in the termini of the reserve tubules has been demonstrated. We have attempted to demonstrate the presence or absence of any material other than $\mathrm{CaCO}_{3}$, as demonstrated by others, in the concretions. We find the concretions not birefringent, insoluble in dilute $\mathrm{NaOH}$ and alcohol, negative for carbohydrates with PAS stain as well as iodine, negative for fats with Sudan black B, consistently positive with urate stains; but we have not been satisfied that the calcium has been entirely removed prior to staining in our material. Therefore, the granules are probably mostly calcareous, with no carbohydrates or lipids, but possibly some nitrogenous material. The corpuscles gradually disappear during the first 3 days in the chick although the little "sacks" that they were in can still be seen. At 4 days no evidence of the corpuscles or "sacks" can be seen; at this time the worms are first ovigerous.

The mature metacercaria fixed (Figs. 11, 12, 13, 14):

Fixed in hot alcohol-formaldehyde-acetic acid fixative, affixed to slides with polyvinyl alcohot, and stained with hematein. Paratype deposited in U. S. National Museum Collection as No. 55621. Many authors have stressed the importance of hot fixatives for preserving the natural proportions of trematodes as well as preventing excessive shrinkage due to contraction. Apparently some variation can be expected with any method. Some of our specimens nearly retained their normal proportions (Fig. 13) and some did not; some shrank when hot AFA 

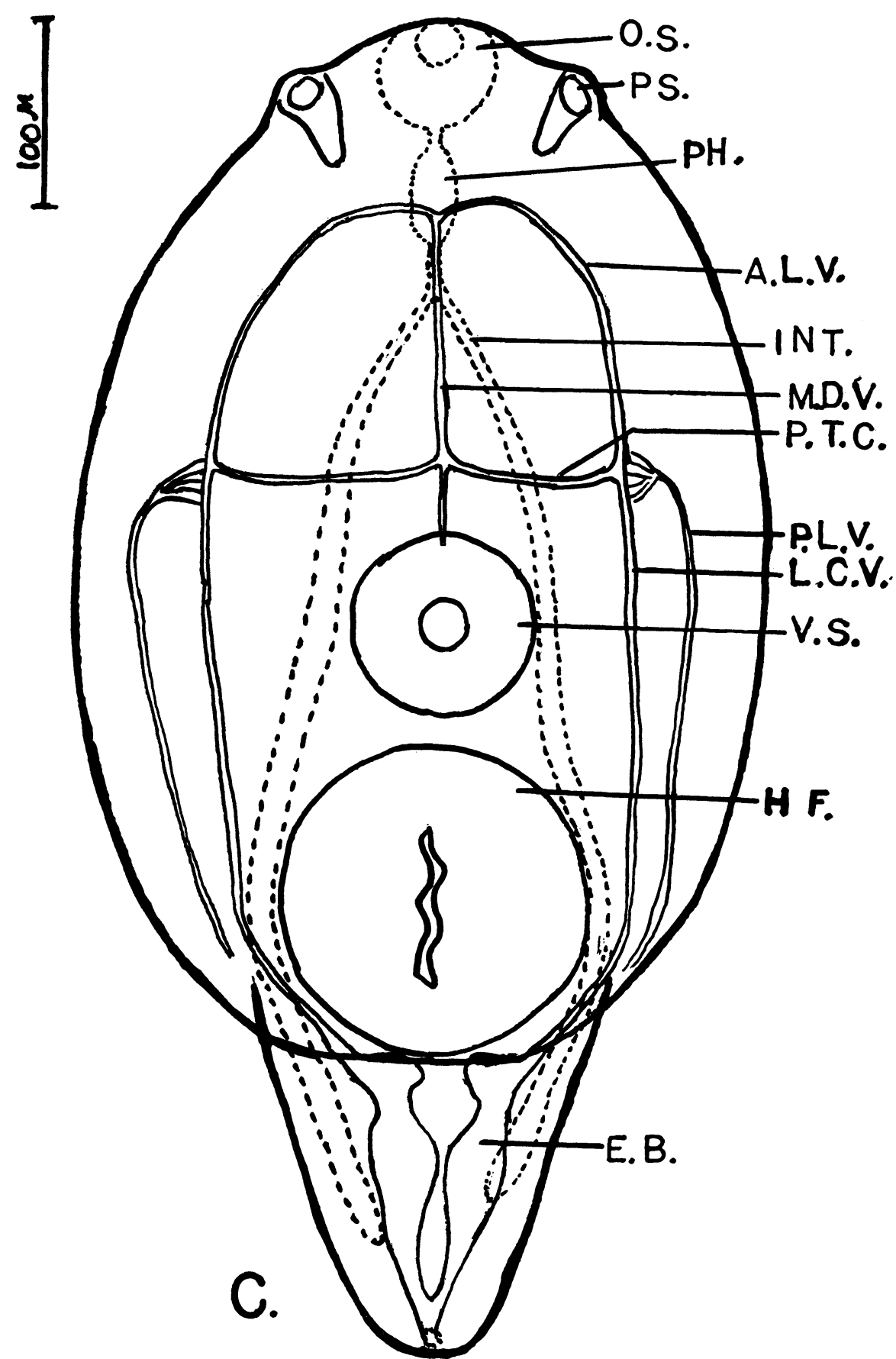

Figure C. Composite drawing of mature metacercaria. Explanation of symbols same as for Plate I. 
was used but some became more extended, and in some (Fig. 14) the body regions lost their normal relationships. All measurements are based on 12 mounted specimens fixed as above. Total length $0.401(0.33-0.5)$; forebody $0.361(0.32-0.387)$ in length by $0.274(0.23-0.27)$ in width; oral sucker $0.05(0.045-0.052)$ in diameter; pharynx $0.04(0.038-0.042) \times 0.020(0.017-$ $0.024)$; esophagus $0.014(0.012-0.026)$ long; ventral sucker to intestinal branching $0.073(0.058-$ $0.086)$; and holdfast $0.103(0.097-0.11)$ in diameter. The intestinal crura extend posteriorly, curve around the holdfast organ and end about midway in the hindbody.

Diplostomulum baeri eucaliae differs from the following Diplostomulum spp. of fish which possess more or less distinct hindbodies: (1) Hystermorpha tribola (Diplostomulum corti) Hughes, 1929, in the presence of the ventral sucker and holdfast organ in the posterior half of the worm instead of about mid-way, in being about half as large, and in possessing a round instead of elongate holdfast organ; (2) D. spathaceum (Rudolphi) in possessing a ventral sucker about half as large as the holdfast organ instead of about the same size, in having oral and ventral suckers of about the same size instead of a larger oral sucker, and in having deeply cupped lateral suckers; (3) from D. ictaluri Haderlie, 1953 in being about onethird as large; and in possessing a ventral sucker about half as large as the holdfast instead of about one-fourth as large; (4) D. phoxini (Faust, 1918) in being nearly twice as large, in having proportionally smaller oral and ventral suckers, in having a different-shaped excretory bladder, and in causing the formation of a cyst-like structure on the brain. (5) D. mordax Szidat and Nani, 1951 in possessing a distinct ventral sucker whereas in the latter it is very small and indistinct; and in possessing round calcareous corpuscles instead of oval. (6) D. petromyzi-fluviatilis (Diesing) in having its intestinal crura extending into the hindbody instead of to the holdfast region as in the latter. The present species also differs from all known Diplostomulum spp. in having been found only in the brain of the stickleback and in causing the formation of 2 tumor-like structures at the postero-lateral aspect of its brain. D. baeri encaliae is not here compared with diplostomula from frogs or those with distinct hindbodies from the eyes of fishes.

Key to the known Diplostomulum species in North American fresh water fish ${ }^{2}$

1. Found in eyes; hindbody indistinct (except D. spathaceum) $\ldots \ldots \ldots \ldots \ldots \ldots \ldots 2$

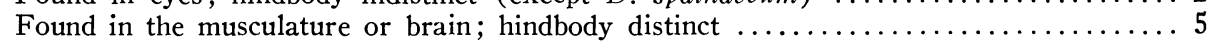

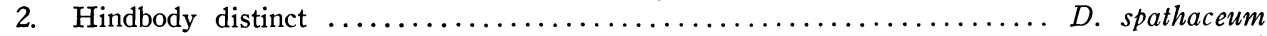

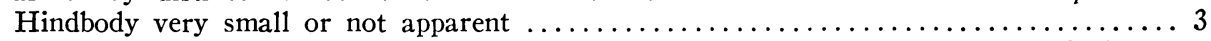

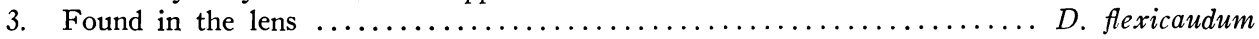

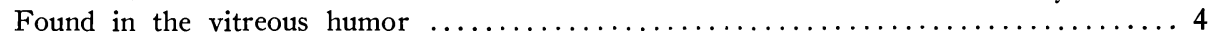

4. Worm three times as long as broad ....................... scheuringi

Worm less than three times as long as broad $\ldots \ldots \ldots \ldots \ldots \ldots \ldots \ldots \ldots$. huronese

5. Found in the brain of Eucalia inconstans .................... baeri eucaliae

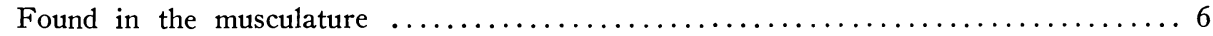

6. Ventral sucker nearly as large as oral sucker ..... D. hysteromorpha triloba (D. corti)

Ventral sucker about half as large as oral sucker $\ldots \ldots \ldots \ldots \ldots \ldots \ldots \ldots$. ictaluri

\section{ACKNOWLEDGMENTS}

We wish to acknowledge the technical assistance given by James B. Hoyme, Omer Larson, and Kathleen Pigott. Dr. J. P. E. Morrison of the Smithsonian Institution, Washington, D. C., kindly identified representative specimens of our snails. We wish to thank Dr. T. Snook of this school for silver staining some cross sections. Dr. G. Dubois, University of Neuchatel, Neuchatel, Switzerland has kindly examined slides of the adult for us.

\footnotetext{
2 There are undoubtedly species that have not been described.
} 


\section{SUMMARY}

Diplostomum baeri eucaliae n. subsp. is described from experimentally infected chicks and the screech owl, Otus asio, and from naturally infected mallard ducks, Anas p. platyrhynchos.

Developmental stages, including the cercaria, are described from the snails, Stagnicola palustris and Stagnicola palustris elodes.

The brook stickleback, Eucalia inconstans, but not Pimephales p. promelas or Fundulus diaphanus menona, was experimentally infected. Exposure of the stickleback to more than 200 cercariae was usually fatal. The development of the diplostomulum in the brain of the fish is described and the metacercaria is differentiated from known species. A key to the known Diplostomulum spp. is presented.

The calcareous corpuscles were positive for calcium, negative for carbohydrates and fats. They stained positively with urate stains, but we are not absolutely sure that urate is present.

\section{References Cited}

Arvy, Lucie And Buttner, Alice 1954 Données sur le cycle evolutif de Diplostomulum phoxini (Faust, 1918). (Trematoda, Diplostomidae). Compt. Rend. Soc. Biol. Paris 239: $1085-1087$.

Ashworth, J. H. and Bannerman, Janet C. W. 1927 On a tetracotyle (T. phoxini) in the brain of the minnow. Tr. Roy. Soc. Edinb. 55: 159-172.

Brown, A. W. 1899 On Tetracotyle petromyzontis, a parasite of the brain of Ammocoetes. Quart. J. Micr. Sci. n.s. 41: 489-498.

Cort, W. W., Ameel, D. J., And Van der Woude, Anne 1951 Early developmental stages of strigeid mother sporocysts. Proc. Helm. Soc., Wash. 18: 5-9.

$\rightarrow-$ AND BRackett, S. 1937 Two new species of strigeid cercariae from the Douglas Lake Region, Michigan. J. Parasitol. 23: 265-280.

Dawes, B. 1952 Trematode life-cycle enacted in a London pond. Nature 170 (4315) : 72-73.

DuboIs, G. 1955 Personal communication.

Hoffman, G. L. 1953 Parasites of fish of Turtle River, North Dakota. Proc. N. Dak. Acad. Sci.: 12-19.

1955 Life-cycle of Diplostomum (baeri?) (Trematoda: Strigeida). J. Parasitol. 41 (Supp1.) : 22 .

$\rightarrow-1956$ The life-cycle of Crassiphiala bulboglossa (Trematoda: Strigeida). Development of the metacercaria and cyst, and effect on the fish hosts. J. Parasitol. 42: 435-444.

Leydig, F. 1853 Zoologische Notizen. 2 Helminthologisches. Ztschr. f. wissensch. Zool. 4: 382-387.

McMullen, D. B. And Beaver, P. C. 1945 Studies on schistosome dermatitis. IX. The life-cycles of three dermatitis-producing schistosomes from birds and a discussion of the subfamily Bilharziellinae (Trematoda: Schistomatidae). Am. J. Hyg. 42: 128-154.

Pellegrino, J. and Macedo, D. G. 1955 A simplified method for the concentration of cercariae. J. Parasitol. 41: 329.

ReEs, Gwendolen 1955 The adult and diplostomulum stage (Diplostomulum phoxini (Faust)) of Diplostomum pelmatoides Dubois and an experimental demonstration of part of the life cycle. Parasitology 45: 295-312.

Szidat, L. And Nani, A. 1951 Diplostomiasis cerebralis del pejerrey. Una grave epizootia que afecta la economia nacional producida por de trematodes que destruyen el cerebro de los pejeuueyes. Proc. Inst. Nac. Invest. Cien. Nat. (Cien. Zool.) 1: 323-384. 


\section{Plate I}

s?

8)
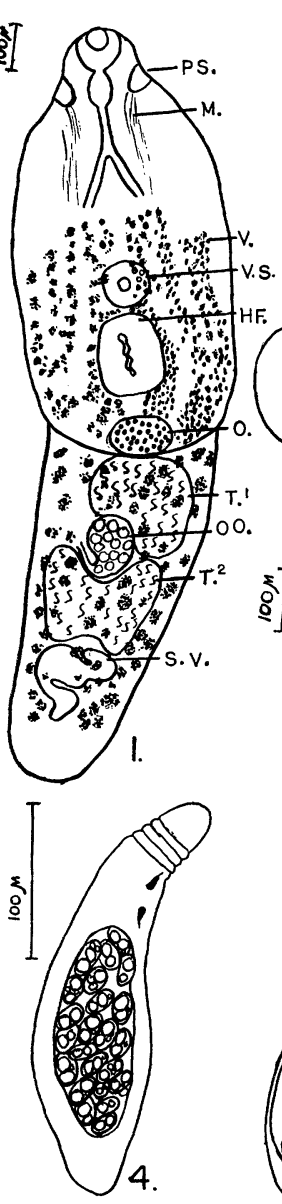

3
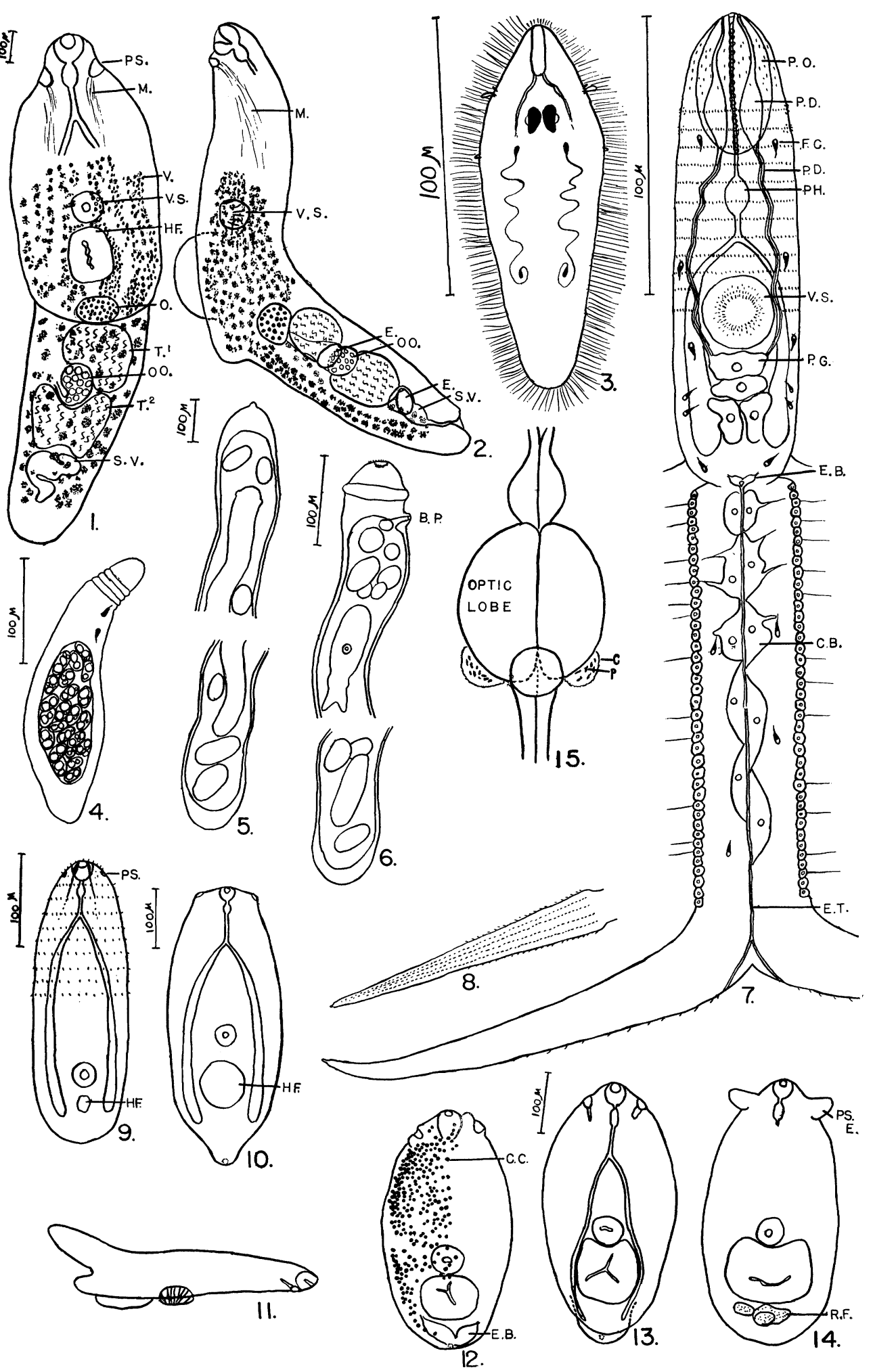
All figures are of Diplostomum baeri eucaliae n. subsp.

FIGURE 1. Adult from experimentally infected chick; ventral view; fixed in hot Bouin's, stained, and mounted; drawn with aid of microprojection.

FIGURE 2. As Figure 1 but lateral view.

FIGURE 3. Miracidium; free hand drawing.

FiguRe 4. Mother sporocyst, 14 days; free hand drawing.

Figure 5. Mother sporocyst, 30 days or more; free hand drawing.

FIGURE 6. Daughter sporocyst, 30 days or more; free hand drawing.

Figure 7. Cercaria; composite drawing.

FIGURE 8. Lateral view of furca of cercaria.

FIgURe 9. Diplostomulum, 5 days; free hand drawing.

FIGURE 10. Diplostomulum, 9 days; free hand drawing.

FIGURE 11. Diplostomulum, mature; lateral view; free hand sketch.

FIGURE 12. Diplostomulum, mature, showing calcareous corpuscles stained with urate stain; drawn with aid of microprojection.

FIGURE 13. Diplostomulum, mature; ventral view; fixed in hot Bouin's, stained and mounted; drawn with aid of microprojection.

FIGURE. 14. Diplostomulum, mature; showing everted pseudosuckers; prepared as Figure 13.

FIGURE 15. Free hand sketch of brain of Eucalia inconstans showing the position of the parasite "sacks."

\section{Abbreviations}

A.L.V.-Anterior lateral vessel; B.P.-Birth Pore; C.-“Cyst"; C.B. Caudal bodies; C.C.-Calcareous corpuscles; E.-Egg; E.B.-Excretory bladder; E.T.-Excretory tubule; F.C.-Flame cell; HF.-Holdfast; INT.-Intestine; L.C.V.-Lateral collecting vessel; M.Muscle; M.D.V.-Median dorsal vessel; O.-Ovary; O.O.-Ootype; O.S.-Oral sucker; P.Parasite; P.D.-Penetration duct; P.G.-Penetration Gland; PH.-Pharynx; P.L.V.Posterior lateral vessel; P.O.-Penetration organ; PS.-Pseudosucker; PS.E.-Pseudosucker everted; P.T.C.-Posterior transverse commisural vessel; R.F.-Reproductive fundament; S.V.-Seminal vesicle; T. ${ }^{1-A n t e r i o r ~ t e s t i s ; ~ T . ~}{ }^{2}$-Posterior testis; V.-Vitellaria; V.S.Ventral sucker. 